\title{
Ketidaksinambungan Litologi dan Karakteristik Pedogenetik pada Beberapa Andisols di Jawa Barat
}

Rina Devnita, Mahfud Arifin, Ridha Hudaya, Apong Sandrawati, dan Ade Setiawan

Departemen Ilmu Tanah dan Sumberdaya Lahan, Fakultas Pertanian Universitas Padjadjaran

Jl. Raya Bandung Sumedang Km 21 Jatinangor

Korespondensi: rina.devnita@unpad.ac.id, rinabursi@yahoo.com

\begin{abstract}
Andisols developed from parent materials of volcanic eruptions. Volcanic eruptions can occur within several periods, resulting in a sequence of soil layers that can differ from each period and produced lithologic discontinuity in the soil profile. Lithologicac discontinuity was investigated in Andisols developed from the eruptions of Mt. Tangkuban Parahu (Holocene, andesitic) and Mt. Tilu (Pleistocene, basaltic) in West Java through morphological observations of three profiles at each location. The results showed that there was lithologic discontinuity in all profiles indicated by changed in color by Munsell Soil Colour Chart, organic carbon, texture and structure as the specific $A$ buried horizon that developed from the parent material of the earlier eruption period than the horizons above. It is recommended to carry out the mineralogical and micromorphological analyses to determine the differences in minerals and micromorphology of the discontinue horizons and carbon-dating analysis in the buried layer to determine the age of the soil and the period of eruption that developed the soil.
\end{abstract}

Keywords: A buried horizon, Munsell Soil Colour Chart, organic carbon, soil mineralogy, soil morphology

\section{PENDAHULUAN}

Ketidaksinambungan litologi (lithologic discontinuity) adalah perubahan signifikan dalam berbagai hal seperti warna, ukuran partikel serta mineralogi yang mewakili perbedaan litologis dalam satu profil tanah (Ahr, et. al., 2016). Hal ini terjadi jika terdapat dua atau lebih bahan induk yang berbeda secara vertikal sehingga menyebabkan terdapat variasi dalam proses pembentukan tanah serta tanah yang dihasilkannya. Pengetahuan tentang ketidaksinambungan litologi memberikan informasi penting tentang proses yang terjadi dalam tanah, yang mendahului proses pembentukan tanah (Ande dan Senjobi, 2010).

Erupsi gunungapi mengeluarkan antara lain bahan-bahan halus seperti abu, pumis dan sinder. Bahan-bahan tersebut merupakan bahan induk untuk terbentuknya tanah vulkanik, yang jika memenuhi sifat-safat tanah andik diklasifikasikan sebagai Andisols (Soil Survey Staff, 2014). Erupsi gunungapi dapat terjadi dalam beberapa periode sehingga Andisols yang terbentuk mempunyai morfologi yang spesifik dan unik, seperti terdapatnya horison tanah yang membentuk ketidaksinambungan litologi (Stoops, et al., 2008). Adanya horison yang berwarna lebih gelap yang ditemukan di lapisan bawah setelah horison yang berwarna lebih terang di atasnya merupakan salah satu ciri ketidaksinambungan litologi. Horison yang lebih gelap tesebut dapat merupakan horison $\mathrm{A}$ tertimbun (A buried horizon) yang lazim dijumpai di bawah horison Bw, BC atau C pada Andisols (Tan, 1984).

Penelitian ini dilakukan pada dua lokasi Andisols yang terdapat di lereng G. Tangkuban Parahu serta G. Tilu. Andisols yang terdapat pada lereng G. Tangkuban Parahu berbahan induk tuf pasir kristal hornblende, lahar lapuk kemerahan, lapisan lapili dan breksi dari G. Dano dan G. Tangkuban Parahu dari zaman Holosen dan disimbolkan dengan Qyd (Silitonga, 2003). Secara administratif lokasi tersebut berada di Desa Cikole, Kecamatan Lembang, Kabupaten Bandung Barat.

Andisols yang terdapat pada lereng G. Tilu berbahan induk tuf, breksi lahar dengan 
sedikit batu apung dan lava dari G. Tilu dari zaman Pleistosen yang disimbolkan dengan Qtl (Alzwar dkk, 1976). Secara administratif lokasi tersebut berada di Desa Pulosari, Kec. Pangalengan, Kab. Bandung.

\section{METODOLOGI}

Analisis kondisi awal dilakukan terhadap satuan peta lahan di lokasi penelitian. Peta yang digunanakan dalam analisis satuan lahan adalah Peta Tanah Kabupaten Bandung skala 1 : 250.000 (Badan Perencanaan Daerah, 2008), Peta Penggunaan Lahan Kabupaten Bandung skala 1 : 25.000 (Badan Perencanaan Daerah, 2008), Peta Kemiringan Lereng Kabupaten Bandung skala 1 : 25.000 (Badan Perencanaan Daerah, 2008) dan Peta Geologi Lembar Bandung, skala $1: 100.000$ (Silitonga, 2003) serta Peta Geologi Lembar Garut dan dan Pangalengan (Alzwar et al., 1976).

Peralatan lapangan yang digunakan adalah GPS (Global Position System), Munsell Soil Color Chart, clinometer, bor tanah (auger), ring sampler, kertas deskripsi, kantong plastik, pisau, meteran dan label. Pengamatan lapangan berupa kemiringan lereng, penggunaan lahan dan morfologi tanah pada profil yang meliputi kedalaman solum, batas dan ketebalan horizon, warna, tekstur, struktur, konsistensi, pori, $\mathrm{pH}$, perakaran, berpedoman kepada Field Book for Soil Describing and Sampling Soils (NSSC, 2002). Contoh tanah diambil dari setiap horison untuk analisis sifat komia dan fisika tanah.

Pengamatan makro-morfologi tanah serta deskripsi profil dan pengambilan sampel tanah dilakukan dengan membuat tiga profil tanah pada setiap lokasi. Pengamatan ketidaksinambungan litologi didasarkan pada pengamatan profil serta hasil analisis kimia terutama C-organik dengan metode Walkley and Black (van Reeuwijk, 1992) Analisis lain yang dilakukan adalah bobot isi (Bielders et. al., 1990) dan $\mathrm{Al}+1 / 2 \mathrm{Fe}$ dengan asam amonium oksalat (van Reeuwijk, 1992).

\section{HASIL DAN PEMBAHASAN}

\subsection{Informasi Fisiografi}

Informasi fisiografi lokasi penelitian disajikan pada Tabel 1. Tabel tersebut menunjukkan bahwa Andisols pada kedua lokasi memiliki umur geologi bahan induk yang berbeda yaitu Holosen (Andisols pada lereng G. Tangkuban Parahu) dan Pleistosen (Andisols pada lereng G. Tilu).

Tabel 3 Informasi Fisiografis Andisols pada lereng G.Tangkuban Parahu dan lereng G.Tilu

\begin{tabular}{|c|c|c|c|c|c|c|c|}
\hline Lokasi & $\begin{array}{l}\text { Sumber } \\
\text { Erupsi/ } \\
\text { Bahan } \\
\text { Induk }\end{array}$ & Umur & Profil & Koordinat & Vegetasi & $\begin{array}{c}\text { Lereng } \\
(\%)\end{array}$ & $\begin{array}{l}\text { Elevasi } \\
\text { (m dpl) }\end{array}$ \\
\hline \multirow[t]{3}{*}{ Cikole } & $\begin{array}{l}\text { G. } \\
\text { Tangkuban } \\
\text { Parahu/ }\end{array}$ & Holosen & TP 1 & $\begin{array}{l}107^{\circ} 38^{\prime} 57.0^{\prime \prime} \\
-06^{\circ} 47^{\prime} 07.7^{\prime \prime}\end{array}$ & $\begin{array}{l}\text { Pinus mercusii dan } \\
\text { Pueraria } \\
\text { phaseoloides) }\end{array}$ & 12 & 1.300 \\
\hline & Andesitik & & TP 2 & $\begin{array}{l}107^{\circ} 38^{\prime} 51.9^{\prime \prime} \\
-06^{\circ} 47^{\prime} 12.5^{\prime \prime}\end{array}$ & Pinus mercusii & 13 & 1.390 \\
\hline & & & TP 3 & $\begin{array}{l}107^{\circ} 38^{\prime} 54.9^{\prime \prime} \\
-06^{\circ} 47^{\prime} 11.6^{\prime \prime}\end{array}$ & $\begin{array}{lr}\text { Pinus } & \text { mercusii, } \\
\text { Pennisetum } & \text { sp.dan } \\
\text { Coffea sp. } & \end{array}$ & 10 & 1.405 \\
\hline \multirow[t]{3}{*}{ Pulosari } & $\begin{array}{l}\text { G. Tilu/ } \\
\text { Basaltik }\end{array}$ & Pleistosen & TL 1 & $\begin{array}{l}107^{\circ} 32^{\prime} 31.4^{\prime \prime} \\
-07^{\circ} 10^{\prime} 49.7^{\prime \prime}\end{array}$ & $\begin{array}{lr}\text { Pinus } & \text { mercusii, } \\
\text { Pennisetum } & \text { sp.dan } \\
\text { Coffea sp. } & \end{array}$ & 10 & 1.484 \\
\hline & & & TL 2 & $\begin{array}{l}107^{\circ} 32^{\prime} 27.5^{\prime \prime} \\
-07^{\circ} 10^{\prime} 58.3^{\prime \prime}\end{array}$ & $\begin{array}{l}\text { Pinus } \quad \text { mercusii, } \\
\text { Pennisetum sp. Coffea } \\
\text { sp. Camellia sinensis }\end{array}$ & 9 & 1.482 \\
\hline & & & TL 3 & $\begin{array}{l}107^{\circ} 32^{\prime} 34.8^{\prime \prime} \\
-07^{\circ} 11^{\prime} 01.8^{\prime \prime}\end{array}$ & $\begin{array}{lr}\text { Pinus mercusii, } & \text { mennisetum } \\
\text { Pen., Coffea } \\
\text { sp. dan Camellia } \\
\text { sinensis }\end{array}$ & 9 & 1.492 \\
\hline
\end{tabular}


Keenam profil berada pada penggunan lahan yang sama, yaitu kebun/perkebunan dengan vegetasi utama tanaman pinus (Pinus mercusii). Kesamaan lain adalah kelas lereng yakni bergelombang/agak miring (9-15\%), dan berada di dataran tinggi dengan elevasi di atas > $1.000 \mathrm{~m} \mathrm{dpl}$. Selain itu, kesamaan lainnya adalah keenam profil tersebut merupakan Andisols dengan regim kelembaban udik dan regim temperatur tanah isohipertermik (Arifin, 1994).

\subsection{Investigasi Sifat-Sifat Tanah Andik}

Investigasi sifat-sifat tanah andik adalah untuk memastikan tanah pada kedua lokasi tersebut adalah Andisols dengan berpedoman pada persyaratan yang dikemukakan oleh Soil Survey Staff (2014). Hasil analisis untuk sifat tanah andik untuk setiap horison disajikan pada Tabel 2 untuk tanah pada lereng G. Tangkuban Parahu dan Tabel 3 untuk tanah pada lereng G. Tilu.

Nilai sifat-sifat tanah andik sampai kedalaman $60 \mathrm{~cm}$ harus menunjukkan bahwa C-organik kurang atau sama dengan $25 \%$; bobot isi lebih kecil atau sama dengan $0,9 \mathrm{~g}$ $\mathrm{cm}^{-3}, \mathrm{Al}_{\mathrm{o}}+1 / 2 \mathrm{Fe}_{\mathrm{o}}$ lebih besar atau sama dengan $2 \%$; dan retensi $\mathrm{P} \geq 85 \%$. Tabel 2 dan Tabel 3 menunjukkan bahwa kriteria tidak hanya sampai kedalaman $60 \mathrm{~cm}$, tetapi terpenuhi untuk seluruh kedalaman. Data profil di kedua lereng tersebut dapat diklasifikasikan sebagai sebagai Andisols. Hal ini sejalan dengan Arifin (1992) yang meneliti beberapa Andisols di Jawa Barat termasuk hasil erupsi Gunung Tangkuban Parahu.

Tabel 2 Hasil Analisis untuk investigasi sifat-sifat tanah andik pada profil G.Tangkuban Parahu

\begin{tabular}{|c|c|c|c|c|c|c|}
\hline Profil & Horison & $\begin{array}{l}\text { Kedalaman } \\
(\mathrm{cm})\end{array}$ & $\begin{array}{c}\text { C-organik } \\
(\%)\end{array}$ & $\begin{array}{l}\text { Bobot Isi } \\
\left(\mathrm{g} \mathrm{cm}^{-3}\right)\end{array}$ & Alo $+1 / 2$ Feo & $\begin{array}{c}\text { Rentensi P } \\
\text { (\%) }\end{array}$ \\
\hline \multirow{10}{*}{ TPR 1} & Ap 1 & $0-14$ & 8,42 & 0,58 & 5,3 & 99,20 \\
\hline & Ap 2 & $14-22$ & 4,71 & 0,61 & 3,4 & 99,70 \\
\hline & Ap 3 & $22-48$ & 4,25 & 0,71 & 3,5 & 99,80 \\
\hline & $\mathrm{BC}$ & $48-58$ & 4,84 & 0,69 & 3,4 & 99,10 \\
\hline & $2 \mathrm{Ab} 1$ & $58-87$ & 9,28 & 0,63 & 3,5 & 99,60 \\
\hline & $2 \mathrm{Ab} 2$ & $87-110$ & 9,45 & 0,69 & 3,9 & 99,50 \\
\hline & $2 \mathrm{BA}$ & $110-119$ & 5,65 & 0,68 & 5,4 & 99,20 \\
\hline & $2 \mathrm{Bw} 1$ & $119-144$ & 3,58 & 0,88 & 6,7 & 99,90 \\
\hline & $2 \mathrm{Bw} 2$ & $144-162$ & 2,62 & 0,71 & 5,8 & 99,80 \\
\hline & $2 \mathrm{BC}$ & $162-200$ & 1,62 & 0,76 & 5,7 & 99,50 \\
\hline \multirow{11}{*}{ TPR 2} & Ap 1 & 0 - 14 & 8,97 & 0,78 & 2,3 & 97,38 \\
\hline & Ap 2 & $14-30$ & 8,95 & 0,70 & 2,6 & 95,81 \\
\hline & Ap 3 & $30-45$ & 8,19 & 0,69 & 4,5 & 95,75 \\
\hline & BA & $45-62$ & 5,62 & 0,87 & 3,9 & 95,71 \\
\hline & Bw 1 & $62-77$ & 3,24 & 0,70 & 4,0 & 96,08 \\
\hline & Bw 2 & $77-90$ & 6,94 & 0,67 & 4,7 & 96,08 \\
\hline & $\mathrm{BC}$ & $90-105$ & 6,49 & 0,74 & 5,3 & 95,85 \\
\hline & $2 \mathrm{Ab} 1$ & $105-115$ & 7,76 & 0,66 & 4,5 & 95,74 \\
\hline & $2 \mathrm{Ab} 2$ & $115-147$ & 8,97 & 0,61 & 4,2 & 95,66 \\
\hline & $2 \mathrm{Ab} 3$ & $147-183$ & 8,97 & 0,74 & 4,3 & 95,36 \\
\hline & $2 \mathrm{Bwb}$ & $183-200$ & 5,62 & 0,66 & 4,7 & 95,65 \\
\hline \multirow{11}{*}{ TPR 3} & Ap 1 & $0-13$ & 8,97 & 0,72 & 3,9 & 96,44 \\
\hline & Ap 2 & $13-32$ & 7,76 & 0,65 & 4,8 & 95,99 \\
\hline & $\mathrm{BC}$ & $32-45$ & 5,34 & 0,72 & 5,2 & 96,51 \\
\hline & $2 \mathrm{Ab}$ & $45-71$ & 7,64 & 0,72 & 4,5 & 96,22 \\
\hline & $2 \mathrm{BA}$ & $71-78$ & 7,41 & 0,67 & 4,4 & 96,21 \\
\hline & $2 \mathrm{Bw} 1$ & $78-126$ & 6,86 & 0,71 & 5,1 & 96,01 \\
\hline & $2 \mathrm{Bw} 2$ & $126-144$ & 1,64 & 0,68 & 5,7 & 96,35 \\
\hline & $2 \mathrm{Bw} 3$ & $144-164$ & 2,54 & 0,76 & 6,4 & 96,09 \\
\hline & $2 \mathrm{Bw} 4$ & $164-172$ & 2,57 & 0,71 & 5,7 & 96,28 \\
\hline & $2 \mathrm{BC} 1$ & $172-184$ & 1,60 & 0,81 & 5,5 & 96,30 \\
\hline & $2 \mathrm{BC} 2$ & $184-200$ & 1,79 & 0,84 & 2,6 & 96,22 \\
\hline
\end{tabular}


Tabel 2 Hasil Analisis untuk investigasi sifat-sifat tanah Andik pada profil G.Tilu

\begin{tabular}{|c|c|c|c|c|c|c|}
\hline Profil & Horison & $\begin{array}{c}\text { Kedalaman } \\
(\mathrm{cm})\end{array}$ & $\begin{array}{c}\text { C-organik } \\
(\%)\end{array}$ & $\begin{array}{c}\text { Bobot isi } \\
\left(\mathrm{g} \mathrm{cm}^{-3}\right)\end{array}$ & $\begin{array}{c}\mathrm{Al}_{\mathrm{o}}+1 / 2 \\
\mathrm{Fe}_{\mathrm{o}}\end{array}$ & $\begin{array}{c}\text { Retensi P } \\
(\%)\end{array}$ \\
\hline \multirow{12}{*}{ TLU 1} & Ap 1 & $0-7$ & 9,48 & 0,62 & 5,3 & 96,73 \\
\hline & Ap 2 & $7-18$ & 9,83 & 0,60 & 3,4 & 96,38 \\
\hline & Ap 3 & $18-31$ & 6,71 & 0,64 & 3,5 & 96,45 \\
\hline & Bw 1 & $31-57$ & 4,20 & 0,63 & 3,4 & 96,57 \\
\hline & Bw 2 & $57-70$ & 2,93 & 0,69 & 3,5 & 96,52 \\
\hline & Bt 1 & $70-79$ & 2,58 & 0,66 & 3,9 & 96,44 \\
\hline & Bt 2 & $79-90$ & 3,72 & 0,65 & 5,4 & 96,50 \\
\hline & $\mathrm{BC}$ & $90-116$ & 3,55 & 0,72 & 6,7 & 96,48 \\
\hline & CB & $116-135$ & 3,01 & 0,80 & 5,8 & 96,47 \\
\hline & $2 \mathrm{AB} 1$ & $135-148$ & 4,21 & 0,74 & 5,7 & 96,42 \\
\hline & $2 \mathrm{Bw} 1$ & $148-162$ & 2,85 & 0,76 & 2,3 & 96,37 \\
\hline & 2 Bw 2 & $162-200$ & 2,32 & 0,64 & 2,6 & 96,33 \\
\hline \multirow{12}{*}{ TLU 2} & Ap 1 & $0-7$ & 7,34 & 0,67 & 4,5 & 98,80 \\
\hline & Ap 2 & $7-12$ & 6,53 & 0,75 & 3,9 & 97,40 \\
\hline & $\mathrm{AB}$ & $12-27$ & 3,62 & 0,62 & 4,0 & 99,30 \\
\hline & Bw 1 & $27-37$ & 3,18 & 0,71 & 4,7 & 99,40 \\
\hline & Bw 2 & $37-46$ & 2,83 & 0,65 & 5,3 & 99,30 \\
\hline & Bw 3 & $46-58$ & 2,10 & 0,64 & 4,5 & 98,90 \\
\hline & Bt 1 & $58-80$ & 1,71 & 0,66 & 4,2 & 99,10 \\
\hline & Bt 2 & $80-99$ & 1,47 & 0,72 & 4,3 & 99,20 \\
\hline & $\mathrm{BC}$ & $99-114$ & 1,06 & 0,65 & 4,7 & 99,90 \\
\hline & $\mathrm{CB}$ & $114-130$ & 1,00 & 0,72 & 3,9 & 99,40 \\
\hline & $2 \mathrm{Ab}$ & $130-156$ & 3,84 & 0,71 & 4,8 & 99,70 \\
\hline & $2 \mathrm{Bw}$ & $156-200$ & 3,61 & 0,67 & 5,2 & 98,90 \\
\hline \multirow{12}{*}{ TLU 3} & Ap 1 & $0-11$ & 10,14 & 0,74 & 4,5 & 96,31 \\
\hline & Ap 2 & $11-19$ & 8,66 & 0,76 & 4,4 & 96,52 \\
\hline & $\mathrm{AB}$ & $19-30$ & 9,98 & 0,64 & 5,1 & 96,19 \\
\hline & Bw 1 & $30-51$ & 6,66 & 0,67 & 5,7 & 96,29 \\
\hline & Bw 2 & $51-65$ & 4,33 & 0,75 & 6,4 & 96,44 \\
\hline & $\mathrm{Bt}$ & $65-75$ & 3,27 & 0,62 & 5,7 & 96,44 \\
\hline & BC & $75-92$ & 3,45 & 0,71 & 5,5 & 96,60 \\
\hline & $2 \mathrm{Ab} 1$ & $92-109$ & 4,76 & 0,65 & 2,6 & 96,55 \\
\hline & $2 \mathrm{Ab} 2$ & $109-126$ & 6,05 & 0,64 & 2,6 & 96,45 \\
\hline & $2 \mathrm{Bw} 1$ & $126-158$ & 3,97 & 0,75 & 5,7 & 96,52 \\
\hline & $2 \mathrm{Bw} 2$ & $158-173$ & 2,20 & 0,62 & 5,5 & 96,51 \\
\hline & $2 \mathrm{Bt}$ & $173-200$ & 2,22 & & 2,9 & 96,27 \\
\hline
\end{tabular}

\subsection{Deskripsi Profil dan Karakteristik Morfologi Andisols}

Deskripsi profil dan foto TPR 1, TPR 2 dan TPR 3 Andisols pada lereng selatan G, Tangkuban Parahu ditampilkan pada Tabel 4, 5 dan 6 serta Gambar 1. Adanya ketidaksinambungan litologi pada ketiga profil mulai terlihat berbagai kedalaman seperti pada kedalaman $58-87 \mathrm{~cm}$ (TPR 1), 105-115 cm (TPR2), dan 45-71 cm (TPR 3) berupa perubahan warna menjadi lebih gelap dibandingkan horison BC di atasnya. Hal ini terlihat pada TPR 1 horison BC $(48-58 \mathrm{~cm})$ yang mempunyai value/chroma yang lebih besar (10YR 3/4) dibanding horison 2 Ab1 (10YR 2/2) dan 2 Ab2 (10YR 2/1). Demikian juga dengan profil TPR 2 , warna horison BC (90-105 cm) adalah 10YR 3/3, lebih tinggi value/chromanya dibandingkan 2 Ab1 (10YR 3/2) dan 2 Ab2 (10 YR 2/2). Hal yang sama terlihat pada proofil TPR 3, warna horison BC $(32-45 \mathrm{~cm})$ lebih tinggi value/chromanya (10YR 3/4) dibandingkan horison $2 \mathrm{Ab}$ (10YR 2/2). Dipahami bahwa makin kecil nilai value dan chromanya, makin gelap tanah tersebut. Perbedaan warna yang menjadi lebih gelap pada horison A yang terimbun dapat dilihat pada Gambar 1.a., 1.b, dan 1.c. 
Tabel 4 Deskripsi Profil dan Karakteristik Morfologi Andisols pada Profil TPR 1

\begin{tabular}{|c|c|c|c|c|c|c|c|c|c|}
\hline Hor & $\begin{array}{l}\text { Ked } \\
(\mathrm{cm})\end{array}$ & Warna & Teks & Str & Kons & Pori & Akar & pH & $\begin{array}{c}\text { Batas } \\
\text { Horison }\end{array}$ \\
\hline Ap 1 & $0-14$ & 10YR 5/6 & $\mathrm{lb}$ & r-sh & l-sg & mak-s, mes-b, mik-b & abb, ams, akb & 5 & baur, rata \\
\hline Ap 2 & $14-22$ & 10YR 4/6 & $\mathrm{lb}$ & r-sh & l-sg & mak-s, mes-b, mik-b & abta,amb, akb & 5 & baur, rata \\
\hline Ap 3 & $22-48$ & $10 \mathrm{YR} 4 / 4$ & $\mathrm{lb}$ & r-sh & al-g & mak-s, mes-b, mik-b & abs, ams, akb & 5 & baur, rata \\
\hline $\mathrm{BC}$ & $48-58$ & 10YR $3 / 4$ & $\mathrm{lb}$ & gb-h & al-g & mak-s, mes-b, mik-b & abs, ams, aks & 5 & jelas, rata \\
\hline $2 \mathrm{Ab} 1$ & $58-87$ & $10 \mathrm{YR} 2 / 2$ & $\mathrm{~d}$ & $\mathrm{r}-\mathrm{h}$ & l-sg & mak-s, mes-b, mik-b & abta,ams, akb & 5 & baur, rata \\
\hline $2 \mathrm{Ab} 2$ & $87-110$ & 10YR 2/1 & d & $\mathrm{r}-\mathrm{h}$ & l-g & mak-s, mes-b, mik-b & abta,ams, akb & 6 & baur, rata \\
\hline $2 \mathrm{BA}$ & $110-119$ & $10 Y R 2 / 3$ & d & gb-h & l-g & mak-s, mes-b, mik-b & abta,ams, aks & 5 & jelas, rata \\
\hline $2 \mathrm{Bw} 1$ & $119-144$ & $10 Y R 3 / 3$ & d & gb-ah & $\mathrm{t}$ & mak-s, mes-b, mik-b & abta,ams, aks & 5 & jelas, rata \\
\hline 2 Bw 2 & $144-162$ & 10YR 3/6 & d & gb-ah & $\mathrm{t}$ & mak-s, mes-b, mik-b & abta,ams, akta & 5 & baur, rata \\
\hline $2 \mathrm{BC}$ & $162-200$ & $10 \mathrm{YR} 4 / 6$ & $\mathrm{~d}$ & gb-ah & $\mathrm{t}$ & mak-s, mes-b, mik-b & abs,ams, aks & 4 & - \\
\hline & an : br-b & rison $\cdot \mathrm{ked}=\mathrm{k}$ & & & & str=struktur; kons=kons & stensi; lb=lempu & & $\begin{array}{l}\text { ebu; } d=\text { debu } \\
-s g=l e m a h, \\
\text { mik-b=mikr } \\
\text { besar tidak }\end{array}$ \\
\hline
\end{tabular}

Tabel 5 Deskripsi Profil dan Karakteristik Morfologi Andisols pada Profil TPR 2

\begin{tabular}{lccccccccc}
\hline \multicolumn{1}{c}{ Hor } & $\begin{array}{c}\text { Ked } \\
\text { (cm) }\end{array}$ & Warna & Teks & Str & Kons & Pori & Akar & pH & $\begin{array}{c}\text { Batas } \\
\text { Horison }\end{array}$ \\
\hline Ap 1 & $0-14$ & 10YR 5/8 & lb & r-sh & l-sg & mak-b, mes-b, mik-b & abs,amb, aksd & 5 & baur, rata \\
Ap 2 & $14-30$ & 10YR 5/6 & lb & r-sh & l-sg & mak-s, mes-b, mik-b & abs,amb, aks & 5 & baur, berombak \\
Ap 3 & $30-45$ & 10YR 4/6 & lb & r-sh & l-sg & mak-s, mes-b, mik-b & abs,amb, aks & 5 & baur, rata \\
BA & $45-62$ & 10YR 5/6 & lb & r-h & al-g & mak-s, mes-b, mik-b & abs,amb, akb & 5 & jelas, rata \\
Bw 1 & $62-77$ & 10YR 3/6 & lb & r-h & al-g & mak-s, mes-b, mik-b & abta,ams, akb & 5 & jelas, rata \\
Bw 2 & $77-90$ & 10YR 4/4 & lb & r-h & al-g & mak-s, mes-b, mik-b & abta,ams, akb & 5 & jelas, rata \\
BC & $90-105$ & 10YR 3/3 & lb & r-sh & ls-g & mak-s, mes-b, mik-b & abta,ams, akb & 5 & jelas, rata \\
2 Ab 1 & $105-115$ & 10YR 3/2 & d & r-sh & l-sg & mak-s, mes-b, mik-b & abta,ams, aksd & 5 & jelas, rata \\
2 Ab 2 & $115-147$ & 10YR 2/2 & d & r-h & s-g & mak-s, mes-b, mik-b & abta,amta, akta & 5 & jelas, rata \\
2 Ab 3 & $147-183$ & 10YR 2/1 & d & r & s-g & mak-s, mes-b, mik-b & abs, ams, aks & 5 & jelas, rata \\
2 Bwb & $183-200$ & 10YR 3/2 & d & gm-s & t & mak-s, mes-s, mik-b & abs, ams, aks & 5 & - \\
\hline
\end{tabular}

Keterangan : hor=horison; ked=kedalaman; teks= tekstur; str=struktur; kons=konsistensi; lb=lempung berdebu; $d=d e b u$; $\mathrm{r}$-sh=remah, sangat halus; gb-h=gumpal bersudut, halus; gb-ah=gumpal bersudut, agak halus; l-sg=lemah, sangat gembur; al-g=agak lemah, gembur; $t=$ teguh; mak-s=makro sedikit; mes- $b=$ =meso banyak, mik-b=mikro banyak; abb=akar besar banyak; ams=akar medium sedang; akb=akar kecil banyak; abta=akar besar tidak ada

Tabel 6 Deskripsi Profil dan Karakteristik Morfologi Andisols pada Profil TPR 3

\begin{tabular}{|c|c|c|c|c|c|c|c|c|c|}
\hline Hor & $\begin{array}{l}\text { Ked } \\
(\mathrm{cm})\end{array}$ & Warna & Teks & Str & Kons & Pori & Akar & pH & $\begin{array}{c}\text { Batas } \\
\text { Horison }\end{array}$ \\
\hline Ap 1 & $0-13$ & 10YR 5/4 & $\mathrm{lb}$ & r-sh & l-sg & mak-b, mes-b, mik-b & abta, amb, akb & 5 & jelas, rata \\
\hline Ap 2 & $13-32$ & $10 Y R 4 / 6$ & $\mathrm{ib}$ & r-sh & l-sg & mak-b, mes-b, mik-b & abta, amb, akb & 5 & jelas, berombak \\
\hline $\mathrm{BC}$ & $32-45$ & $10 Y R 3 / 4$ & $\mathrm{lb}$ & r-sh & l-sg & mak-s, mes-b, mik-b & abta, ams, akb & 5 & jelas, rata \\
\hline $2 \mathrm{Ab} 1$ & $45-71$ & 10YR $2 / 2$ & $\mathrm{~d}$ & r-sh & l-sg & mak-s, mes-b, mik-b & abta, ams, akb & 5 & jelas, rata \\
\hline $2 \mathrm{BA}$ & $71-78$ & 10YR $3 / 6$ & d & $r-h$ & s-g & mak-s, mes-b, mik-b & abta, ams, aks & 5 & jelas, rata \\
\hline $2 \mathrm{Bw} 1$ & $78-126$ & 10YR 4/6 & $\mathrm{d}$ & $\mathrm{r}-\mathrm{h}$ & l-g & mak-s, mes-s, mik-b & abta, ams, aks & 6 & baur, berombak \\
\hline 2 Bw 2 & $126-144$ & 10YR 5/6 & $\mathrm{d}$ & $\mathrm{r}-\mathrm{h}$ & $s-g$ & mak-s, mes-b, mik-b & abta, amta, aks & 5 & baur, rata \\
\hline $2 \mathrm{Bw} 3$ & $144-164$ & 10YR 5/6 & $d$ & $\mathrm{r}-\mathrm{h}$ & l-g & mak-s, mes-b, mik-b & abta, amta, aks & 5 & baur, rata \\
\hline $2 \mathrm{Bw} 4$ & $164-172$ & 10YR 5/6, & d & $\mathrm{r}-\mathrm{h}$ & $\mathrm{t}$ & mak-s, mes-b, mik-b & $\begin{array}{l}\text { mak-s, mes-b, } \\
\text { mik-b }\end{array}$ & & baur, rata \\
\hline $2 \mathrm{BC} 1$ & $172-184$ & 10YR 4/6 & $\mathrm{d}$ & $g b-b$ & $\mathrm{t}$ & mak-s, mes-s, mik-b & abta, amta, aks & 5 & baur, rata \\
\hline 2 BC 2 & $184-200$ & $10 Y R 4 / 4$ & $\mathrm{~d}$ & gm-b & $\mathrm{t}$ & mak-s, mes-s, mik-b & abta, amta, aks & 5 & - \\
\hline
\end{tabular}

Warna yang lebih gelap pada horison A ditunjang oleh nilai C-organik yang meningkat dari 4,84\% menjadi 9,28 dan 9,45\% (TPR 1), $6,49 \%$ menjadi 7,76 dan $8,97 \%$ (TPR 2), dari
5,34\% menjadi 7,64\% (TPR 3). Peningkatan kembali C-organik pada kedalaman yang cukup jauh dari permukaan tanah adalah tidak lazim, kecuali menunjukkan horison yang 
sudah berkembang sebelumnya atau horison yang tertimbun.

Perubahan morfologi tidak saja diperlihatkan oleh warna tanah yang menjadi lebih gelap, tetapi juga oleh perubahan lainnya seperti struktur yang berubah dari gumpal bersudut menjadi kembali remah (TPR 1), konsistensi gembur menjadi sangat gembur
(TPR 2), serta perubahan tekstur dari lempung berdebu (lb) menjadi debu (d). Hal ini terjadi pada ketiga profil yang dianalisis (TPR 1, TPR 2, ddan TPR 3). Perubahan tekstur dan stuktur yang diperlihatkan oleh suatu profil tanah merupakan salah satu ciri terjadinya ketidaksinambungan litologi (Lorz et. al., 2010).

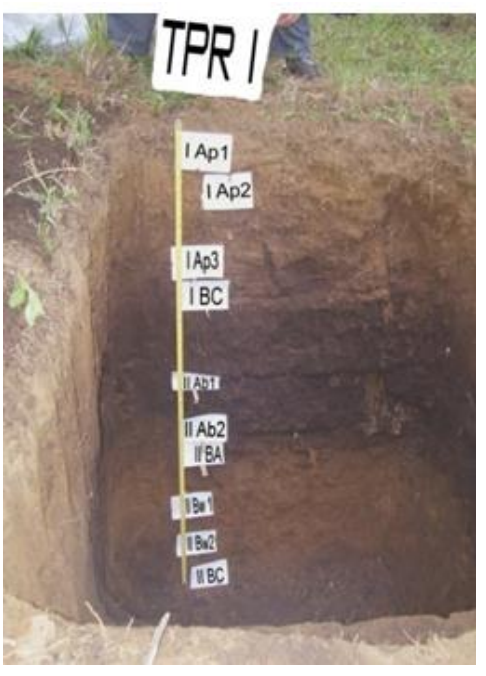

a

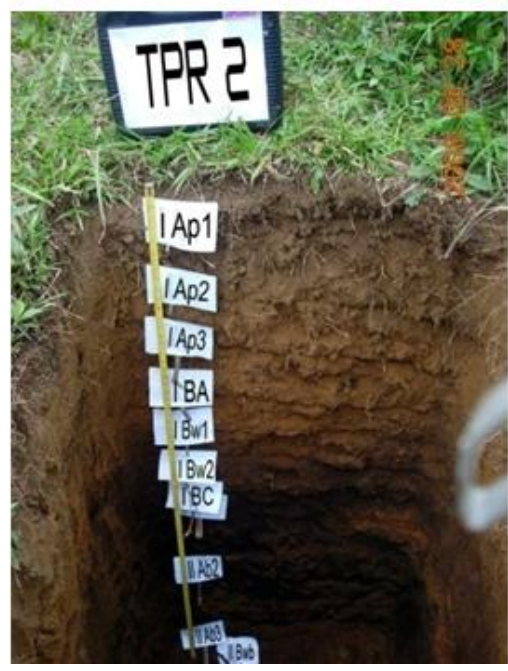

b

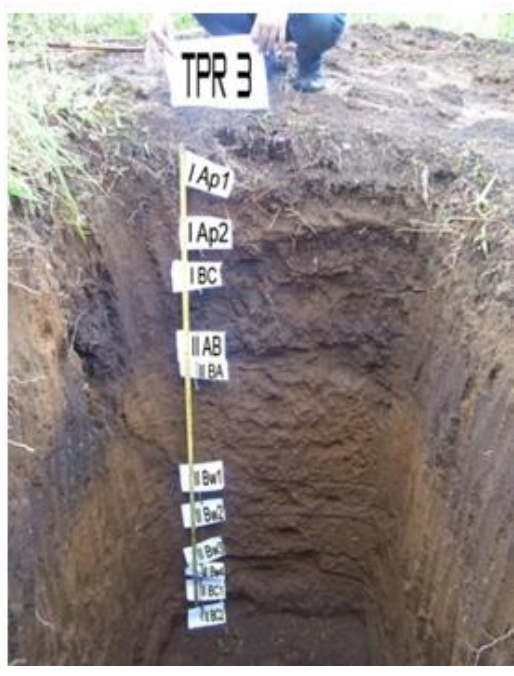

Gambar 1 Profil Tanah Hasil Erupsi G. Dano dan G. Tangkuban Parahu pada Lereng Selatan G. Tangkuban Parahu, TPR 1 (a), TPR 2 (b), dan TPR 3 (c)

Horison A tertimbun atau A buried horizon (2 Ab) pada profil-profil ini ditemukan pada kedalaman $58 \mathrm{~cm}$ (TPR1), $105 \mathrm{~cm}$ (TPR 2) dan $45 \mathrm{~cm}$ (TPR 3). Hal ini menunjukkan bahwa tanah di atas horison A tertimbun, yang merupakan tanah dengan perkembangan bahan induk dari hasil erupsi yang terbaru atau terakhir masih relatif dangkal. Mengacu pada peta geologi (Silitonga, 2003) daerah ini berbahan induk kuarter (Qyd) berumur Holosen. Umur yang relatif muda tesebut direfleksikan dengan kedalaman tanah yang relatif masih dangkal.

Deskripsi ketiga profil ini menunjukkan bahwa hanya terdapat dua ketidaksinambungan litologi. Tidak ada batasan berapa ketidaksinambungan litologi harus terdapat dalam satu profil, karena itu tergantung pada berapa periode erupsi yang membentuk tanah hingga kedalaman $200 \mathrm{~cm}$ dari permukaan tanah. Meskipun diketahui ada horison tanah dengan bahan induk yang berbeda dari lapisan di atasnya, tidak dketahui berapa umur lapisan yang tertimbun tersebut karena tidak ada analisis umur paruh melalui carbondating untuk menentukan kapan erupi yang terjadi yang membentuk lapisan tanah tersebut. Analisis lain yang dapat lebih mendukung ketidaksinambungan litologi adalah analisis mineralogi dan mikromorfologi (Stoops et. al., 2008).

\subsection{Deskripsi Profil dan Karakteristik Morfologi Andisols pada lereng selatan G. Tilu}

Deskripsi profil dan foto TLU 1, TLU 2 dan TLU 3 Andisols pada lereng selatan G, Tilu ditampilkan pada Tabel 7, 8 dan 9 serta Gambar 2. Sepertinya halnya pada profil TPR, ke-tidaksinambungan litologi pada ketiga profil TLU ini juga mulai terlihat berbagai keda-laman seperti pada kedalaman 135-148 cm (TLU 1), 130-156 cm (TLU 2), dan 92-109 cm (TLU 3) berupa perubahan warna menjadi 
lebih gelap dibandingkan horison $\mathrm{CB}$ atau $\mathrm{BC}$ di atasnya.

Perubahan warna terlihat pada TLU 1 horison CB (116-135 cm) yang mempunyai value/ chroma yang lebih besar dibanding horison $2 \mathrm{Ab}$. Demikian juga dengan profil TLU 2, warna horison CB (114-130 cm) adalah 10YR 5/6, lebih tinggi value/chromanya dibandingkan $2 \mathrm{Ab}(10 \mathrm{YR}$ 4/6). Hal yang sama terlihat pada proofil TLU 3, warna horison BC
(75-92 cm) lebih tinggi value/chromanya (10YR 5/8) dibandingkan horison 2 Ab1 (10YR 4/4) dan 2 Ab2 (10YR 4/6).

Makin kecil nilai value dan chroma menunjukkan warna tanah yang makin gelap. Warna yang lebih gelap ini sejalan dengan nilai $\mathrm{C}$-organik yang meningkat yang terjadi pada ketiga profil, yaitu: $3,01 \%$ menjadi 4,21\% (TLU 1), 1,00\% menjadi 3,84\% (TLU 2), dan 3,45\% menjadi 4,76 dan 6,05\% (TLU 3).

Tabel 7 Deskripsi Profil dan Karakteristik Morfologi Andisols pada Profil TLU 1

\begin{tabular}{|c|c|c|c|c|c|c|c|c|c|}
\hline Hor & $\begin{array}{l}\text { Ked } \\
(\mathrm{cm})\end{array}$ & Warna & Teks & Str & Kons & Pori & Akar & pH & $\begin{array}{c}\text { Batas } \\
\text { Horison } \\
\end{array}$ \\
\hline Ap1 & $0-7$ & $10 \mathrm{YR} 3 / 3$ & $\mathrm{lb}$ & r-sh & l-sg & mak-s, mes-sd, mik-b & abta, ams, aks & 5 & $\begin{array}{l}\text { baur, } \\
\text { berombak }\end{array}$ \\
\hline Ap2 & $7-18$ & $10 Y R 3 / 4$ & $\mathrm{~d}$ & $\mathrm{r}-\mathrm{h}$ & s-g & mak-s, mes-s, mik-b & abta, amta, akb & 5 & baur, rata \\
\hline Ap3 & $18-31$ & $10 Y R 4 / 4$ & $\mathrm{~d}$ & r-ag & $s-g$ & mak-s, mes-s, mik-b & abta, ams, akta & 5 & baur, rata \\
\hline Bw1 & $31-57$ & $10 \mathrm{YR} 4 / 6$ & $\mathrm{lb}$ & $g b-h$ & l-g & mak-s, mes-b, mik-b & abta, amta, akta & 5 & jelas, rata \\
\hline Bw2 & $57-70$ & 10YR 5/8 & $\mathrm{lb}$ & gb-ah & $\operatorname{l-g}$ & mak-s, mes-s, mik-b & abta, amta, akta & 5 & $\begin{array}{l}\text { baur, } \\
\text { berombak }\end{array}$ \\
\hline Bt1 & $70-79$ & 10YR 5/6 & $\mathrm{lb}$ & gb-ah & $\mathrm{t}$ & mak-s, mes-s, mik-b & abta, amta, akta & 5 & jelas, rata \\
\hline Bt2 & $79-90$ & 10YR 6/8 & llb & gb-ah & $\mathrm{t}$ & mak-s, mes-s, mik-b & abs, amb, akb & 5 & jelas, rata \\
\hline $\mathrm{BC}$ & $90-116$ & $\begin{array}{c}7.5 \text { YR 5/8; } \\
10 \text { YR 6/8 }\end{array}$ & llb & gb-ah & s-g & mak-s, mes-b, mik-b & abs, ams, akb & 5 & jelas, rata \\
\hline $\mathrm{CB}$ & $116-135$ & 10YR 5/8 & llb & gb-ah & s-g & mak-s, mes-s, mik-b & abs-amb, -akb & & jelas, rata \\
\hline $2 \mathrm{Ab}$ & $135-148$ & 10YR 5/6 & llb & gb-ah & $\mathrm{t}$ & mak-s, mes-s, mik-b & abs, ams, aks & 5 & jelas, rata \\
\hline $2 \mathrm{Bw} 1$ & $148-162$ & $10 \mathrm{YR} 4 / 6$ & $\mathrm{~d}$ & gb-af & s-g & mak-s, mes-sd, mik-b & abs, ams, aks & 5 & jelas-rata \\
\hline 2 Bw2 & $162-200$ & 10 YR 5/6 & d & gb-ah & s-g & mak-s, mes-sd, mik-b & abta, ams, aks & 5 & - \\
\hline
\end{tabular}

Tabel 8 Deskripsi Profil dan Karakteristik Morfologi Andisols pada Profil TLU 2

\begin{tabular}{cccccccccc}
\hline Hor & $\begin{array}{c}\text { Ked } \\
\text { (cm) }\end{array}$ & Warna & Teks & Str & Kons & Pori & Akar & pH & $\begin{array}{c}\text { Batas } \\
\text { Horison }\end{array}$ \\
\hline Ap1 & $0-7$ & 10YR 3/3 & lb & r-sh & l-sg & mak-s, mes-b, mik-b & abta, amb, akb & 5 & jelas, rata \\
Ap2 & $7-12$ & 10YR 4/3 & lb & r-sh & l-sg & mak-s, mes-s, mik-b & abs, ams, akb & 5 & jelas, rata \\
Ab & $12-27$ & 10YR 3/4 & lb & r-sh & s-g & mak-s, mes-s, mik-b & abs, amb, akb & 5 & jelas, rata \\
Bw1 & $27-37$ & 10 YR 4/4 & lb & r-ah & s-g & mak-s, mes-sd, mik-b & absd, amb, akb & 5 & jelas, rata \\
Bw2 & $37-46$ & 10YR 3/6 & llb & gb-h & s-g & mak-s, mes-sd, mik-b & abs, amsd, akb & 5 & jelas, rata \\
Bw3 & $46-58$ & 10YR 4/4 & llb & gb-h & s-g & mak-s, mes-s, mik-b & abta, ams, aks & 5 & jelas, rata \\
Bt1 & $58-80$ & 10YR 4/6 & llb & gb-ah & t & mak-s, mes-s, mik-b & abta, ams, aks & 5 & jelas, rata \\
Bt2 & $80-114$ & 10 Yh 5/6 & llb & gb-ah & t & mak-s, mes-s, mik-b & abta, amta, aks & 5 & jelas, rata \\
BC & $99-114$ & 10YR 5/8 & lb & gb-ah & t & mak-s, mes-s, mik-b & abta-amta, -aks & 5 & jelas, rata \\
CB & $114-130$ & 10YR 5/6 & lb & gb-ah & t & mak-s, mes-s, mik-b & abta, amta, aks & 5 & jelas, rata \\
2 Ab & $130-156$ & 10YR 4/6 & d & r-ah & s-g & mak-s, mes-s, mik-b & abta, amta, akta & 5 & jelas-rata \\
2 Bw & $156-200$ & 10YR 4/4 & d & gb-ah & s-g & mak-s, mes-s, mik-b & abta, amta, akta & 5 & - \\
\hline
\end{tabular}

Keterangan : hor=horison; ked=kedalaman; teks= tekstur; str=struktur; kons=konsistensi; lb=lempung berdebu; $d=d e b u$;

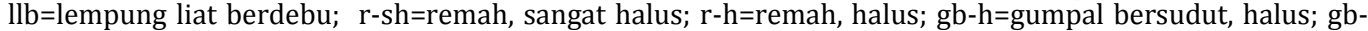
ah=gumpal bersudut, agak halus; gm-s=gumpal membulat, sedang; l-sg=lemah, sangat gembur; s-g=sedang, gembur; al-g=agak lemah, gembur; l-g= lemah, gembur; $\mathrm{t}=$ teguh; mak-s=makro sedikit; mes-b=meso banyak, mik-b=mikro banyak; mes-sd=meso, sedang; abs=akar besar sedikit ; ams=akar medium sedikit; akb=akar kecil banyak; abta=akar besar tidak ada; amta=akar medium tidak ada 
Tabel 9 Deskripsi Profil dan Karakteristik Morfologi Andisols pada Profil TLU 3

\begin{tabular}{|c|c|c|c|c|c|c|c|c|c|}
\hline Hor & $\begin{array}{l}\text { Ked } \\
(\mathrm{cm})\end{array}$ & Warna & Teks & Str & Kons & Pori & Akar & pH & Batas Horison \\
\hline Ap1 & $0-11$ & $10 Y R 3 / 3$ & $\mathrm{lb}$ & r-sh & l-sg & mak-s, mes-b, mik-b & abb, amb, akb & 5 & jelas, rata \\
\hline Ap2 & $11-19$ & $10 Y R 3 / 4$ & $\mathrm{lb}$ & $\mathrm{r}-\mathrm{h}$ & l-sg & mak-s, mes-b, mik-b & abb, ams, aks & 5 & jelas, rata \\
\hline $\mathrm{AB}$ & $19-30$ & $10 \mathrm{YR} 4 / 4$ & $\mathrm{~d}$ & r-sh & s-g & mak-s, mes-s, mik-b & abta, amta, aks & 5 & jelas, rata \\
\hline Bw1 & $30-51$ & 10 YR $3 / 6$ & $\mathrm{~d}$ & $\mathrm{r}-\mathrm{h}$ & $s-g$ & mak-s, mes-s, mik-b & abs, amb, aks & 5 & jelas, berombak \\
\hline Bw 2 & $51-65$ & 10YR 4/6 & llb & gb-h & s-g & mak-s, mes-s, mik-b & abta, ams, ata & 5 & baur, rata \\
\hline $\mathrm{Bt}$ & $65-75$ & 10YR 5/6 & llb & gb-h & $s-g$ & mak-s, mes-s, mik-b & abs, ams, akta & 5 & baur, berombak \\
\hline $\mathrm{BC}$ & $75-92$ & 10YR 5/8 & $\mathrm{llb}$ & r-ah & $\mathrm{g}$ & mak-b, mes-b, mik-s & abta, ams, ata & 5 & baur, rata \\
\hline $2 \mathrm{Ab} 1$ & $92-109$ & $10 Y R 4 / 4$ & $\mathrm{~d}$ & r-ah & $\mathrm{t}$ & mak-b, mes-b, mik-b & abta, ams, ata & 6 & jelas, rata \\
\hline $2 \mathrm{Ab} 2$ & $109-126$ & $10 \mathrm{YR} 4 / 6$ & $\mathrm{~d}$ & $\mathrm{r}-\mathrm{ah}$ & $s-g$ & mak-s, mes-b, mik-s & abta-ams, -aks & 6 & jelas, rata \\
\hline $2 \mathrm{Bw} 1$ & $126-158$ & 10YR 5/6 & $\mathrm{lb}$ & gb-ah & $\mathrm{t}$ & mak-s, mes-b, mik-s & abta, amta, aks & 5 & baur, rata \\
\hline $2 \mathrm{Bw} 2$ & $158-173$ & 10YR 5/8 & $\mathrm{d}$ & gb-ah & $s-t$ & mak-b, mes-b, mik-s & $\begin{array}{l}\text { abta, amta, } \\
\text { akta }\end{array}$ & 5 & baur-rata \\
\hline $2 \mathrm{Bt}$ & $173-200$ & 10YR 6/8 & $\mathrm{d}$ & gm-ah & s-g & mak-s, mes-s, mik-b & $\begin{array}{l}\text { abta, amta, } \\
\text { akta }\end{array}$ & 5 & - \\
\hline tera & gan : hol & & & & $\mathrm{eks}=$ & $\begin{array}{l}\text { s; gm-s=gumpal me } \\
\text { mbur; l-g= lemah, g }\end{array}$ & $\begin{array}{l}\text { Kons=konsistensi; } \\
\text {-h=remah, halus; } \\
\text { bulat, sedang; l-sg } \\
\text { bur; t=teguh; mal }\end{array}$ & & $\begin{array}{l}\text { pung berdebu; } \\
\text { umpal bersudut, } \\
\text { sangat gembur; } \\
\text { ro sedikit; mes- } \\
\text { s=akar medium }\end{array}$ \\
\hline
\end{tabular}

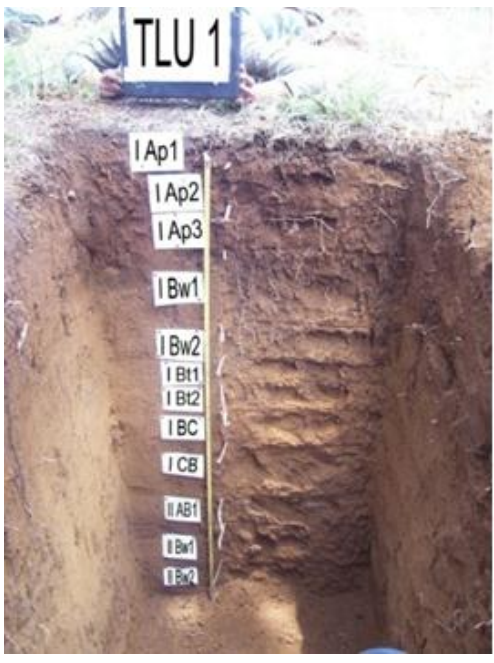

a

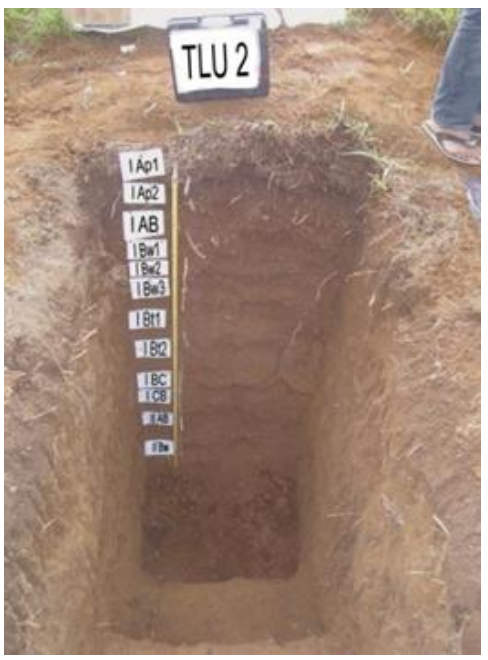

b

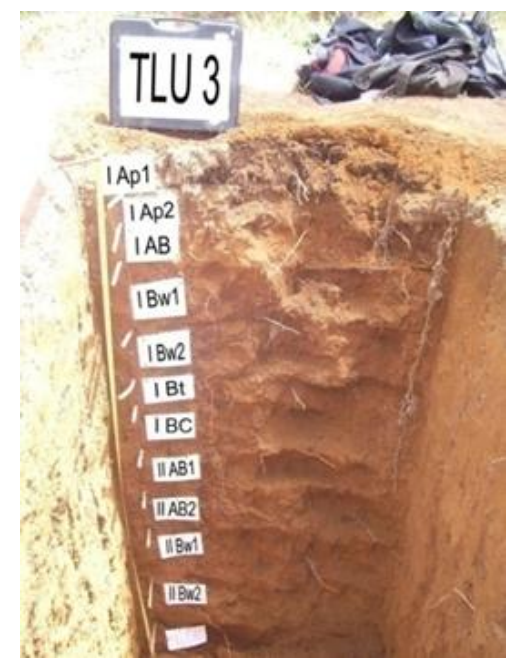

C

Gambar 2 Profil Tanah Hasil Erupsi G. Tilu pada Lereng Selatan G. Tilu; TLU 1 (a), TLU 2 (b), dan TLU 3 (c)

Perubahan warna hoison tanah pada profil TLU dapat dilihat pada Gambar 2.a, 2.b dan 2.c. Warna tanah pada ketiga profil ini lebih terang dibandingkan warna pada profil TPR. Namun, jika persyaratan sifat-sifat tanah Andik telah terpenuhi, warna tanah tidak dipermasalahkan. Olehkarena itu, hal ini tidak menggugurkan klasifikasi tanah ini sebagai Andisols, karena warna gelap bukanlah persyaratan sebagai Andisols seperti yang banyak diasumsikan.

Perubahan morfologi tidak saja diperlihatkan oleh warna tanah yang menjadi lebih gelap, tetapi juga oleh perubahan lainnya seperti struktur yang berubah dari gumpal bersudut menjadi remah (TLU 2), konsistensi teguh menjadi gembur (TLU 2).

Horison A tertimbun ( $2 \mathrm{Ab}$ ) pada profil TLU ini ditemukan pada kedalaman sekitar $100 \mathrm{~cm}$ atau lebih dalam yaitu $135 \mathrm{~cm}$ (TLU 1), $130 \mathrm{~cm}$ (TLU 2) dan $92 \mathrm{~cm}$ (TLU 3). Dibandingkan degan profil TPR, tanah yang berkembang di atas horison A tertimbun pada profil TLU lebih dalam. Hal ini diperkirakan sejalan dengan umur perkembangan tanahnya yang lama lebih lama atau lebih tua yaitu dari zamanan Pleistosen disimbolkan dengan Qtl. 
Ketidaksinambungan litologi pada profil ini, seperti halnya TPR juga terdapat dua bahan induk. Stoops et. al., (2008) menambahkan bahwa analisis mineralogi dan mikromorfologi diharapkan dapat dilakukan untuk memperkuat kesimpulan adanya ketidaksinambungan litologi. Informasi mengenai umur tanah tertimbun tersebut yang dapat dianalisis melalui umur karbon.

\section{KESIMPULAN}

Tanah yang terrdapat pada lereng selatan G. Tangkuban Parahu dan lereng selatan Gunung Tilu adalah Andisols, berdasarkan hasil analisis sifat-sifat tanah andik pada profil tanah di lokasi tersebut. Terdapat ketidaksinambungan litologi pada Andisols hasil erupsi G. Tangkuban Parahu dan G. Tilu di Jawa Barat. Perubahan morfologi (warna dan struktur) memperlihatkan ketidaksinambungan litologi. Ketidaksinambungan litologi akan lebih akurat jika didukung data mineralogi, mikromorfologi dan umur karbon.

\section{Ucapan Terima Kasih}

Penulis mengucapkan terima kasih kepada Prof. Eric Van Ranst dari Department of Geology and Soil Science Ghent University, Belgia untuk fasilitas analisis C-organik, Al-o dan Fe-o (oksalat) dan retensi P. Ucapan terima kasih juga dialamatkan kepada mahasiswa Adit, Hamdani dan Rio yang membantu pekerjaan di lapangan.

\section{DAFTAR PUSTAKA}

Alzwar, M., N. Akbar, dan S. Bachri. 1976. Peta Geologi Lembar Garut dan Pamengpeuk. Dir. Geologi. Dep. Pertambangan, R.I. Bandung.

Ahr, S.W., L.C. Nordt, and R.J. Schaetzl. 2016. Lithologic Discontinuities in Soils. Dalam Ahr, S.W., L.C. Nordt, and R.J. Schaetzl (eds). The International Encyclopedia of Geography. John Wiley \& Sons, Ltd.
Ande, O. T. and B. Senjobi. 2010. Lithologic discontinuity and pedogenetic characterization on an aberrant toposequence associated with a rock hill in South Western Nigeria. International Journal of the Physical Sciences. 5(5): 596-604.

Arifin, M. 1994. Pedogenesis Andisol Berbahan Induk Abu Volkan Andesit dan Basalt pada Beberapa Zona Agroklimat di Daerah Perkebunan Teh Jawa Barat. Disertasi Doktor. Institut Pertanian Bogor.

Arnalds, O., C. T. Hallmark and L. P. Wilding. 1995. Andisols from Four Different Regions of Iceland Soil Science Society of America Journal Abstract - 59 (1), p. 161-169

Badan Perencanaan Daerah (Bapeda). 2008. Peta Jenis Tanah Kabupaten Bandung, Jawa Barat, Skala 1 : 125.000. Badan Perencanaan Tata Ruang dan Lahan. Bandung

Badan Perencanaan Daerah (Bapeda). 2008. Peta Penggunaan Lahan Kabupaten Bandung, Jawa Barat, Skala 1 : 125.000. Badan Perencanaan Tata Ruang dan Lahan. Bandung

Badan Perencanaan Daerah (Bapeda). 2008. Peta Kemiringan Lereng Kabupaten Bandung, Jawa Barat, Skala 1 : 125.000. Badan Perencanaan Tata Ruang dan Lahan. Bandung

Bielders C.L.L,, W. De Backer, B. Delvaux B. 1990. Particle density of volcanic soils as measured with a gas pycnometer. Soil Science Society of America Journal 54:822-826

Lorz, C., M. Frühauf, R. Mailänder, and J. D. Phillips. 2010. Lithologic Discontinuities in Cover Beds Influencing Soil Evolution and Soil Properties. Geophysical Research Abstracts. 12. 
National Soil Survey Center (NSSC). 2002. Field Book for Describing and Sampling Soils Version 2.0. Natural resources Conservation Service. United State Departement of Agriculture. 219 p.

Silitonga, P. H. 2003. Peta Geologi Lembar Bandung. Departemen Energi dan Sumber Daya Mineral .

Soil Survey Staff. 2014. Keys to Soil Taxonomy. $12^{\text {th }}$ ed. Natural Resources Conservation Service. 332 p.

Stoops, G., M. Gérard, and O. Arnalds. 2008. A Micromorphological Study of Andosol Genesis in Iceland. In. S. Kapur and G. Stoops. New Trends in Soil Micromorphology. Springer. pp 6789.

Tan, K. H. 1984. Andosols. A Hutchinson Ross Benchmark Book. Van Nostrand. Reinhold Company

Van Reeuwijk, L. P. 1992. Procedure for Soil Analysis. Fourth Edition. ISRIC. Wageningen. The Netherland. $56 \mathrm{p}$. 